\title{
Explaining Why There is Something Rather than Nothing
}

\author{
Andrew Brenner ${ }^{1}$
}

Received: 3 September 2019 / Accepted: 6 April 2020 / Published online: 7 June 2020

(c) The Author(s) 2020

\begin{abstract}
It is sometimes supposed that, in principle, we cannot offer an explanation for why there is something rather than nothing. I argue that this supposition is a mistake, and stems from a needlessly myopic conception of the form explanations can legitimately take. After making this more general point, I proceed to offer a speculative suggestion regarding one sort of explanation which can in principle serve as an answer to the question "why is there something rather than nothing?" The suggestion is that there may be something rather than nothing in virtue of the truth of certain sorts of subjunctive conditionals.
\end{abstract}

\section{Introduction}

This paper concerns the question "why is there something rather than nothing?" The words "why is there something rather than nothing?" have been used to ask a number of distinct questions (Brenner 2016)—e.g., "why are there any contingent things?", "why are there any concrete things?", "why does anything whatsoever exist?" Despite the fact that the sentence "why is there something rather than nothing?" can be read in multiple ways, it will often prove useful to understand this sentence as if it refers to a single determinate question. So, in what follows I'll sometimes refer to the sentence "why is there something rather than nothing?" as "the Question." There are two construals of the Question which particularly interest me in this paper: 1.why does anything concrete exist? and 2.why does anything whatsoever exist? ${ }^{1}$

\footnotetext{
${ }^{1}$ I focus my attention on these two construals of the Question for two reasons. First, these are probably the two most popular construals of the Question, although people discussing the Question do not always make explicit which construal of the Question they have in mind. Second, these two construals of the Question are apt to be regarded as particularly difficult to answer, in virtue of the nature of explanation. As we'll see momentarily, this paper concerns the nature of explanation, as it relates to our attempts to answer the Question.
}

Andrew Brenner

andrew.t.brenner@gmail.com

1 Department of Religion and Philosophy, Hong Kong Baptist University, 224 Waterloo Road, Kowloon Tong, KLN, Hong Kong 
Two comments on these two construals of the Question: First, neither question is explicitly contrastive, while the Question, as usually formulated, is contrastive (why is there something rather than nothing?). The remarks I make in this paper are also relevant to contrastive formulations of these questions (e.g., "why does anything whatsoever exist, rather than nothing?"). Second, the first construal of the Question refers to things which are "concrete." Concrete objects are to be distinguished from abstract objects. There is some controversy regarding the exact manner in which we should demarcate the abstract from the concrete. For my purposes I don't need to enter into this controversy. I will simply stipulate that a necessary (although not sufficient) condition for an object's being abstract is that it is causally inert, or in any case that it never causes anything else to exist. Abstract objects may have various other features in addition to being causally inert, but those features of abstract objects will not concern us in this paper.

The Question asks for an explanation. An answer to the Question would therefore presumably either provide an explanation for why there is something rather than nothing, or it would note that there is no explanation for why there is something rather than nothing.

Discovering an explanation for why there is something rather than nothing is a notoriously intractable endeavor, and this is particularly true with respect to the two construals of the Question which concern us here. This intractability stems, I'll argue below, from a myopic conception of the form explanations can legitimately take, especially insofar as causal explanation is regarded as the only legitimate form of explanation. This point is not new. Other philosophers have argued that potential explanations for why there is something rather than nothing need not be restricted to types of explanations, such as causal explanation, which seem ill-suited to the task (cf. Lange 2013). In this paper I aim to further defend this point, and help make room for types of explanations which are not on conceptual grounds disqualified from serving as answers to the Question. I'll argue that grounding explanations are in principle capable of answering the Question, although this is only true of grounding explanations with certain special features. If I'm right about that, then grounding answers to the Question represent a potentially fruitful line of inquiry to pursue for future work on the Question.

Here's my plan for the remainder of this paper. In Sect. 2 I argue that coming up with an explanation for why there is something rather than nothing can seem like an intractable or impossible endeavor mainly as a result of our viewing the Question through the lens of a needlessly restricted conception of the form that explanations can legitimately take (e.g., that explanations must be causal). In Sect. 3 I argue that grounding explanations might answer the Question, and I provide some suggestions regarding the form such grounding explanations might take. In Sect. 4 I respond to some objections. Section 5 concludes the paper.

\section{Why is the Question so Intractable?}

Here's a road map for this section: In this section I address whether coming up with an explanation for why there is something rather than nothing is as impossible an endeavor as some philosophers have supposed it is. The view that there could be 
no explanation for why there is something rather than nothing, or no such explanation which we could discover, is motivated by a myopic conception of the form that explanations can legitimately take, and in particular is motivated by a view of explanation according to which only causal explanations of existence are legitimate. In response I note that there are non-causal explanations, including potential noncausal explanations for why there is something rather than nothing. Such explanations are similar in important respects to explanations we sometimes employ in other contexts. Lange (2013) has recently made similar points, and proposed his own tentative non-causal explanation for why there is something rather than nothing. After a brief examination of Lange's proposed explanation, I proceed to present, in Sect. 3, my own tentative suggestions regarding the sorts of non-causal explanations which might be capable of successfully answering the Question.

Philosophers who think that it is impossible to discover an explanation for why there is something rather than nothing generally seem to work with a conception of explanation according to which we can only explain why something exists by citing something else which exists. So, for example, Robert Nozick writes that

The question appears impossible to answer. Any factor introduced to explain why there is something will itself be part of the something to be explained, so it (or anything utilizing it) could not explain all of the something - it could not explain why there is anything at all. Explanation proceeds by explaining some things in terms of others, but this question seems to preclude introducing anything else, any explanatory factors. Some writers conclude from this that the question is ill-formed and meaningless. But why do they cheerfully reject the question rather than despairingly observe that it demarcates a limit of what we can hope to understand? (Nozick 1981: 115) ${ }^{2}$

\section{Similarly, Carl Hempel writes that}

The riddle has been constructed in a manner that makes an answer logically impossible: and scientific explanation can hardly be held to be limited because it cannot satisfy a logically inconsistent requirement... No theory, no conceptual scheme, can explain the existence of anything without assuming the existence of something (Hempel 2001: 341; quoted in Lange 2013: 239)

Causal explanations in particular seem to be the wrong sorts of explanations in this context. Causal explanations for why anything whatsoever exists would presumably appeal to some cause which, of course, exists. But something which exists cannot provide an explanation for why anything whatsoever exists, since it would, under those circumstances, have to provide an explanation for why it exists. ${ }^{3}$ For the same reason, a causal explanation for why anything concrete exists could not appeal to a concrete cause. But it seems as if this sort of explanation could not appeal to any other cause either-concrete objects are generally contrasted with abstract objects,

\footnotetext{
2 While Nozick writes that the Question "appears impossible to answer," he does not ultimately endorse the idea that it is impossible to answer.

3 Here I assume that nothing can cause itself to exist.
} 
and abstract objects are, as I conceive of them in this paper (and as most philosophers conceive of them), causally inert.

But there are non-causal explanations. There may be some non-causal explanation for why there is anything concrete, or for why there is anything whatsoever. For example, axiarchists such as John Leslie maintain that there is something rather than nothing because it is good for there to be something rather than nothing (Leslie 1979). Alternatively, Nozick and Peter van Inwagen suggest that there may be something rather than nothing simply because there are more possible worlds where there is something than there are worlds where there is nothing (Nozick 1981: 127-128, van Inwagen 1996). Yet another explanation for why there is something rather than nothing is in terms of a necessarily existing concrete being, who creates everything else which exists. Leibniz, for example, argued that the answer to the question "why is there something rather than nothing" could only be found in "a necessary being, which carries the reason for its existence within itself" (1714 [1714]: 262, Sect. 7-8). In other words, on this proposal, there is something rather than nothing because one of the things which exists exists of metaphysical necessity. While we might then go on to give a causal explanation for why everything other than the necessary being exists, we do not thereby give a causal explanation for why there is something rather than nothing. Rather, the explanation for why there is something rather than nothing is in terms of a metaphysically necessary truth, one which, Leibniz emphasizes, does not stand in need of further explanation.

While any non-causal explanation for why there is something rather than nothing will likely be highly speculative, such explanations need not be so far removed from explanations given in other domains of inquiry that they can be dismissed outright. Axiarchist explanations for why there is something rather than nothing bear some resemblance to moral explanations given by moral explanationists, as when, for example, Nicholas Sturgeon claims that Hitler did what he did because he was morally depraved (Sturgeon 1988: 234, 243-244). There are, of course, important disanalogies between axiarchist explanations and the sort of moral explanation cited by Sturgeon, not least of which being that Sturgeon's moral explanations may very well be causal explanations. The point is simply that some philosophers maintain, independently of axiarchism, that moral or axiological facts can explain non-moral or non-axiological facts-e.g., that there is something rather than nothing, or that Hitler behaved in a particular manner. Nozick's and van Inwagen's explanation (in terms of there being more possible worlds where there is something than there are worlds where there is nothing) may be, as Sorensen (2017: §1) suggests, an equilibrium explanation, a type of explanation sometimes appealed to in science (Sober 1983). What's more, Nozick's and van Inwagen's proposed explanation for why there is something rather than nothing resembles Boltzmann's famous explanation for why entropy tends to increase in isolated systems (cf. Sorensen 2017: §1, Kotzen 2013: 217-218). Given the state of a system at some time, there are far more high entropy states toward which it might evolve in some subsequent time than there are low entropy states. Assuming the system in question is just as likely to evolve into any of these given subsequent states, it follows that it will be more likely to evolve into a high entropy state than into a low entropy state (cf. Callender 2016: §2). Leibniz's explanation 
for why there is something rather than nothing seems to be an essentialist explanation-a necessary being exists insofar as that being "carries the reason for its existence within itself." Essentialist explanations also appear outside of discussions of the Question. For example, perhaps Socrates' singleton set contains Socrates as a member because it is essential to that set that it contains Socrates as a member. Or perhaps we can explain why a just society will have such-and-such features by noting that it is part of the nature or essence of justice that it have those features (cf. Glazier 2017: 2871-2872).

More generally, non-causal explanations occur frequently in science and everyday life. Lange (2013) makes the same point in response to the concern that any explanation for why there is something rather than nothing must be non-causal and so, allegedly, objectionable. Lange goes on to suggest his own tentative non-causal explanation for why there is something rather than nothing. Perhaps, Lange suggests, there is something whose existence is required by the laws of nature. And while, given our current ignorance of the most fundamental natural laws, we may not be able to offer any plausible candidate for the thing(s) whose existence is required by the laws of nature, we may have some idea what sort of thing(s) might be such that its existence is required by those laws. Lange argues, for example, that within classical Newtonian physics absolute space and time exist of natural necessity, insofar as their existence is required by the laws of nature. Lange continues:

Of course, the world is not actually governed by classical physics. But, plausibly, some fundamental things have their existence required by law in the same way as space and time do in the version of classical physics that we have been considering. Perhaps the Higgs field (posited by the Standard Model as responsible for the masses of elementary particles, and whose existence is being tested experimentally as of this writing) is required by the laws - or perhaps the thing required by the laws is something that has not yet even been hypothesized and out of which space and time themselves emerge. In any case, the same considerations I have sketched regarding absolute space and time in classical physics (under one interpretation) plausibly apply to some entity or other, whatever the laws of nature turn out to be (Lange 2013: 246)

We might go on to ask why the relevant laws of nature hold, especially if they hold only contingently. But even if there is no explanation for why the relevant laws obtain, those laws may nevertheless legitimately be cited as part of an explanation for why there is something rather than nothing. When we ask "why is there something rather than nothing?" we are asking why anything exists, or why things of a particular sort of exist (e.g., concrete things). To say that some law of nature holds is not to say that anything exists, or that anything, say, concrete, or contingent exists. Laws are not things (or at any rate we need not think of them as things), to be quantified over or included in our ontology. Although Lange does not put it in these terms, we might think that we can quantify over laws without being ontologically committed to them (cf. Azzouni 2007). Alternatively, we might say that any talk of "laws" 
holding or obtaining can be paraphrased in such a manner that it becomes clear that one need not quantify over laws. ${ }^{4}$

I do not know if Lange's proposal is correct, in part because, as Lange admits, we don't know what fundamental laws of nature obtain. It is hard to know, then, whether the actual fundamental laws of nature vindicate Lange's proposal. But Lange's proposal seems to me to be pointing in the right direction, at least in one respect, which is why I have discussed it at length. Lange has tried to identify an explanans (or a type of explanans) which is such that 1 . it does not involve or cite the existence of anything, and 2. is such that it can explain why things of a certain sort exist. This is just the sort of explanation we will need in order to explain why there is something rather than nothing. Here Lange follows in the footsteps of other philosophers who have attempted to discover an explanation for why there is something rather than nothing. Nicholas Rescher writes, for example, that "...there is no discernible reason why an existential fact cannot be grounded in nonexistential ones, and why the existence of substantial things cannot be explained on the basis of some nonsubstantial circumstance or principle whose operations can constrain existence in something of the way in which equations can constrain nonzero solutions" (Rescher 2013: 286).

In subsequent sections of this paper I follow Lange's speculations with some speculations of my own. In the following section I will suggest that certain sorts of grounding explanations may, in principle, serve as explanations for why there is something rather than nothing. Like Lange, I don't claim to have identified the correct explanation for why there is something rather than nothing. My goal is more modest: to identify a type of explanation which is, in principle, capable of explaining why there is something rather than nothing, as a possible avenue for future research on the Question.

\section{Grounding Answers to the Question}

Grounding has recently received a great deal of attention from metaphysicians. Grounding occurs when one thing happens in virtue of some other thing's happening, or when one fact obtains in virtue of some other fact's obtaining. So, for example, disjunctions hold in virtue of, and so are grounded in, their true disjuncts. Truths at least sometimes hold in virtue of, and so are grounded in, their truthmakers-e.g., the truth-value of the proposition $<$ dogs exist $>$ is grounded in the dogs which exist, or the fact that dogs exist. Composite objects exist, and have various properties, in virtue of, and so are grounded in, the existence and properties of their proper parts. And so on.

Some philosophers think that grounding is a relation between facts (Rosen 2010), some think that it is a relation between things of any ontological category (Schaffer 2009), and some think that it is best represented with a sentential operator, rather than by reference to a relation (Fine 2001). It will become clear later in this paper

\footnotetext{
${ }^{4}$ For example, we can say things like " $p$ is naturally necessary" without obviously quantifying over natural laws.
} 
that I don't think that grounding must be regarded as a relation, and in particular I don't think that grounding must be understood in terms requiring ontological commitment to facts. I'll return to this issue in Sect. 4. For convenience I sometimes write as if grounding is a relation between things, or a relation between facts.

Grounding explanations explain some thing(s) (e.g., some fact(s)) in terms of its being grounded in some other thing(s) (e.g., some other fact(s)). ${ }^{5}$ So, for example, this shirt's being red is grounded in, and so explained by, its being crimson. This act's being morally impermissible is grounded in, and explained by, its being an act of wanton cruelty. Notably, grounding explanations are not causal explanations, since (pure) grounding explanations do not appeal to causation. For example, an act's being a wanton act of cruelty can explain, via grounding, why the act is morally impermissible, even if it does not cause the act to be morally impermissible.

The sorts of grounding explanations which most concern us here are those grounding explanations in which something's existence is explained by whatever grounds its existence. We saw one example above: composite objects are generally thought to exist because their proper parts exist, and perhaps because those proper parts are appropriately configured. If you want to make a table, for example, what you do is take some objects (e.g., some pieces of wood) and configure them so that they begin to compose a table. In this case, many people assume, the table is brought into existence by its proper parts. Obviously there's a causal component to this process, insofar as the table is caused to exist by your causal interaction with its proper parts. But there is also a non-causal explanation for the table's existence, in terms of its being grounded in its proper parts. Other examples of this sort, where something's existence is explained by whatever grounds its existence, may include: sets whose existence is grounded in, and so explained by, the existence of their members; social groups whose existence is grounded in, and so explained by, the existence and/or configuration of the people making up the group (assuming, as some philosophers do, that this isn't just an instance of part/whole explanation); and the existence of everything other than God being grounded in, and so explained by, God's creative or sustaining activities (as in, e.g., Pearce 2017; Bohn 2018). ${ }^{6}$

The examples of grounding explanations just cited appeal to the existence of something or other in their explanans. For example, the grounding explanation for the existence of the table cites the existence of other things, the table's proper parts. But any grounding explanation for why there is anything whatsoever will not be able to cite among its explanans any existing thing. Similarly, any grounding explanation for why anything concrete exists will not be able to cite among its explanans any

\footnotetext{
5 Some philosophers contend that A's grounding B just is A's (metaphysically) explaining B, while other philosophers think that grounding merely "backs" (but is not identical with) the relevant sorts of explanations. (For some discussion, see Raven 2015: $\$$, Thompson 2016; Maurin 2019.) For my purposes, either option is fine.

6 Theists generally think that God's creative activities causally explain why everything other than God exists. The grounding explanation I have in mind in the main body of the paper is, however, the distinct non-causal explanation for the existence of everything other than God, in terms of the existence of everything other than God being grounded in God's creative or sustaining activities.
} 
existing concrete thing. Are any such explanations conceivable? Yes, or at any rate so I'll now argue.

For starters, it is worth noting that in some respects grounding explanations seem particularly apt for answering the Question. As we saw above, causal explanations are non-starters - any cause we might cite in our explanation for why there is something rather than nothing will be among those things for which we are seeking an explanation. What's more, grounding explanations are generally thought to be synchronic. This is precisely the sort of explanation we will need to explain why there is something rather than nothing. A diachronic explanation for why there is something rather than nothing will have to place its explanans at some time prior to (or at any rate distinct from) any time at which anything exists. But it is doubtful whether there is any such time. It's also worth noting that, given the fact that the sorts of grounding explanations which interest me are synchronic, they are compatible with a range of cosmological scenarios-e.g., they are compatible with the notion that the Universe began to exist, as well as the notion that the Universe has always existed.

I'll now provide two examples of the sorts of grounding explanations for why there is something rather than nothing which I have in mind. While I do not endorse either of these explanations, they serve to illustrate the form that grounding explanations for why there is something rather than nothing might take. Explanations of this sort are not, on conceptual grounds, disqualified from serving as answers to the Question.

Start with Leslie's axiarchism, which I briefly mentioned above. According to Leslie there is something rather than nothing because it is good that there is something rather than nothing. While Leslie does not, as far as I'm aware, put it in these terms, we could think of the axiarchist explanation for why there is something rather than nothing as a grounding explanation-there being something rather than nothing is grounded in its being good for there to be something rather than nothing. The explanans here doesn't seem to involve or tacitly appeal to anything which exists, anything which might itself be among the things for whose existence we are seeking an explanation.

Strictly speaking, we should say that there being something rather than nothing is not grounded in its being good for there to be something rather than nothing, but rather is grounded in those things which exist. The existence of some or all of the particular things which exist will in turn be given an explanation in axiarchist terms-i.e., some or all of the things which exist (or which existed in the past) are such that they exist in virtue of the fact that it is good for them to exist. ${ }^{7}$ Something like this point can be made regarding any grounding answer to the Question of the sort I have in mind in this paper: there being something rather than nothing is grounded in whatever exists, and those things which exist exist in virtue of the fact

\footnotetext{
7 Leslie himself suggests in various places that God might exist because it is good for God to exist (see, e.g., Leslie 2001). If that's right, then perhaps there is something rather than nothing because various particular things exist (i.e., God and God's creations), and one of those particular things (God) exists because it is good for it to exist.
} 
that some non-existential fact or state of affairs obtains (e.g., in virtue of the fact that it is good for them to exist). ${ }^{8}$

Here is a second example of a potential grounding answer to the Question. This example comes from a certain sort of phenomenalism which has recently been defended by Pelczar (2019). According Pelczar, physical facts are reducible to facts about "potentials for experience." While Pelczar doesn't put his thesis in quite these terms, it seems to me that his view could be described as the thesis that physical objects exist in virtue of the truth of various counterfactuals regarding sense data. ${ }^{9}$ For example, if a table exists this will be because various counterfactuals are true: if someone were to be in such-and-such a location then they would have such-andsuch visual impressions; if someone were to be in such-and-such a location then they would have such-and-such tactile sensations; etc. This sort of phenomenalism provides a neat answer to the Question: some or all of the things which exist exist in virtue of the truth of various counterfactuals regarding sense data. Notably, these counterfactuals do not appeal to anything's existence. It can be true, for example, that if someone were to be in such-and-such circumstances then they would have such-and-such sense experiences even if there aren't any agents capable of having phenomenal episodes.

I don't endorse this sort of phenomenalism (or, for that matter, any other sort of phenomenalism). I discuss this sort of phenomenalism here because with the aid of this sort of phenomenalism we can construct explanations of a certain form, and it is explanations of this form which seem to me to be worth investigating if we aim to answer the Question. In this case some or all of the things which exist are grounded in, and explained by, the truth of certain subjunctive conditionals, namely subjunctive conditionals regarding sense data. This is a promising strategy for explaining why there is something rather than nothing because the subjunctive conditionals in question do not appeal to the existence of anything, anything which might be among the things for whose existence we seek an explanation. Perhaps, then, we should be looking for grounding explanations of this sort (where the ground is a subjunctive conditional) when we seek grounding explanations for why there is something rather than nothing, beyond the two grounding explanations just described. In fact, we might also interpret the axiarchist answer to the Question in this manner: there being something rather than nothing is grounded in the truth of a certain subjunctive conditional, namely a conditional to the effect that it would not be good if nothing existed.

Explanations involving subjunctive conditionals in this manner are not so different from explanations many philosophers are already willing to endorse. For example, perhaps you think that simpler theories are, all other things being equal, more likely to be true, because the world is more likely to be simple rather than complex. Well, you now seem to be endorsing just the sort of mysterious metaphysical principle endorsed by, say, the axiarchist. While the axiarchist thinks that there is something rather than nothing because there being something rather than nothing

\footnotetext{
8 Thanks here to Maetias Skipper.

9 Thanks to Robin Stenwall for useful discussion of this point.
} 
is a good state of affairs, the proponent of the view that simpler states of affairs are, all other things being equal, more likely to be actual can be expected to endorse the view that some states of affairs fail to obtain because they are relatively complex states of affairs. The explanans in this case (that some state of affairs would be relatively complex, if it were to obtain) is the truth of a certain subjunctive conditional.

Interestingly, many philosophers are surprised that there is something rather than nothing precisely because it would be simpler if there was nothing - as Leibniz famously put it, "a nothing is simpler and easier than a something" (1714 [1714]: $262, \S 7)$. These philosophers seem to be surprised that a particular grounding explanation involving a subjunctive conditional does not obtain, namely a grounding explanation wherein there is nothing in virtue of the fact that it would be more complex if there was something. If these philosophers regard this grounding explanation as intelligible (in which things do not exist in virtue of the truth of a certain subjunctive conditional), then they should regard the proposed grounding explanations discussed above intelligible as well (in which things do exist in virtue of the truth of a certain subjunctive conditional).

\section{Objections and Responses}

There are a few objections I would like to address.

Objection: We have no good grounds for thinking that the alleged "grounding" explanations I discuss above are in fact grounding explanations, rather than some other sort of explanation.

Response: It is at least somewhat controversial what sorts of explanation, if any, should be classified as "grounding" explanations. I think that if we've got a noncausal explanation, which seems sufficiently analogous to paradigmatic grounding explanations, then we should probably classify the explanation as a grounding explanation. I think that the alleged grounding explanations I discuss in this paper meet that criterion. But in any case, perhaps it isn't so important whether the explanations in question should be thought of as grounding explanations. My main goal in this paper is to identify a type of explanation which might in principle serve as an explanation for why there is something rather than nothing, and it is of secondary importance whether that type of explanation should be classified as a grounding explanation specifically.

Objection: There seems to be an explanatory gap between the sorts of subjunctive conditionals I identify and the existence of anything. Why, for example, would its being good for something to exist ground the actual existence of anything?

Response: Many grounding explanations arguably involve this sort of explanatory gap (Schaffer 2017a). There seems to be such an explanatory gap, for example, in a table's existence being grounded in (and so explained by) there being things arranged table-wise. It is also worth noting, however, that the grounding explanations for why there is something rather than nothing might, when suitably developed, fail to involve such an apparent explanatory gap. The only way to know for sure is to develop candidate explanations of this sort (if there are any to be found, besides the two discussed above). 
Objection: The grounding explanations for why there is something rather than nothing are not "something from nothing explanations," since they explain the existence of some things in terms of other things, namely abstract objects. For example, the axiarchist explanation for why there is something rather than nothing appeals to the obtaining of a particular fact, namely that it would be good if something existed, or that it would not be good if nothing existed. Facts are abstract objects. More generally, the proposed grounding answers to the Question discussed above appeal to true subjunctive conditionals. Conditionals are abstract objects. Similarly, metaphysical laws are abstract objects. Just as natural laws govern causation, metaphysical laws govern grounding (cf. Wilsch 2015; Glazier 2016; Rosen 2017; Schaffer $2017 b$ ). If that's right, then any appeal to grounding requires one to be ontologically committed to metaphysical laws. ${ }^{10}$

Response: If the explanans of the grounding explanations for why there is something rather than nothing appeal to abstract objects, then they cannot provide an explanation for why anything whatsoever exists. Nevertheless, they may still be able to provide an explanation for why anything concrete exists. But in any case, I don't think that we need to regard the explanans involved in these grounding explanations as involving appeals to abstract objects. It can be true that, say, it would be good if something existed, even if there are no abstract objects (e.g., facts, conditionals) to represent that truth. Similarly, metaphysical laws can obtain even if strictly speaking there aren't any such things as metaphysical laws (just as, according to Lange, natural laws can obtain even if there aren't any such things as natural laws). ${ }^{11}$ These are points for which I can't hope to argue here, since to do so would take us far afield into contentious debates regarding abstract objects and when, if ever, we should believe in such objects. ${ }^{12}$

But let's concede, for the sake of argument, that we should believe in the sorts of abstract objects at issue (e.g., facts) in order to endorse grounding explanations for why there is something rather than nothing. Nevertheless, a grounding explanation for why there is something rather than nothing may still ultimately appeal to explanans which do not involve the existence of anything. ${ }^{13}$ For example, consider some subjunctive conditional of the form if $A$ had been the case, then $B$ would have been the case. Perhaps there is some fact corresponding to the truth of that conditional: [if

\footnotetext{
10 See Goldschmidt (2013: 18-19) for a similar objection to Lange's proposed explanation for why there is something rather than nothing.

11 Alternatively, perhaps we shouldn't think of grounding as being governed by metaphysical laws. While I'm comfortable with the idea of metaphysical laws, I'm not sure that grounding must be understood in terms requiring or appealing to metaphysical laws. What's more, the grounding explanations for why there is something rather than nothing which I discuss in this paper do not explicitly appeal to the notion of metaphysical law, nor do they obviously require metaphysical laws (unless grounding in general requires such laws).

12 Although see Putnam (2004: Part 1, Lectures 3-4), which argues that ethical statements can be true, even if there are no objects which those ethical statements describe (e.g., abstract moral properties or facts). We could presumably make a similar point regarding axiological statements. See Fine (2001) for a conception of grounding according to which grounding is not a relation between facts, but rather is perspicuously expressed using a grounding sentential operator.

13 Thanks to an anonymous referee for pointing this out to me.
} 
A had been the case, then B would have been the case]. Now, the grounding explanation for why there is something rather than nothing will, let us suppose, appeal to the existence or obtaining of the fact [if A had been the case, then B would have been the case]. But the existence or obtaining of this fact in turn will have an explanation, namely in terms of its being the case that if A had been the case, then $B$ would have been the case-the existence or obtaining of the fact that that conditional is true is explained by the conditional's being true. It follows, then, that the grounding explanation for why there is something rather than nothing will ultimately appeal to an explanans which does not involve or appeal to anything's existing, namely its being the case that if A had been the case, then B would have been the case.

Objection: The arguments given above employ an objectionable double standard. Grounding, it is alleged, can occur even if there are no things doing the grounding, but by contrast causation cannot occur unless there exists some thing(s) doing the causing. This is why grounding explanations might, in principle, serve as answers to the Question, while, it is alleged, causal explanations cannot, since any causal explanations would cite things whose existence is among the things for which the Question seeks an explanation. What gives?

Response: The assumption that causation requires things to do the causing seems to me to be very plausible. It is also born out in extant accounts of causation, which generally take causes to be events or substances (and so "things"). By contrast, the view that grounding is not a relation (and so may not require ontological commitment to grounds) is endorsed by some prominent grounding theorists (see, e.g., Fine 2001 for the view that grounding is best expressed using a grounding sentential operator, rather than by reference to a grounding relation).

It is sometimes claimed that there are cases of causation by absence or causation by omission. If that's right, then perhaps sometimes causes need not be things. ${ }^{14}$ It is controversial whether such causation by absence or omission really occurs, but leave that concern aside. Sometimes when people discuss "causation by absence" or "causation by omission" they think that "absences" or "omissions" are things. The notion that there is "causation by absence" or "causation by omission" will only serve as a counterexample to my claim that causes are invariably things if "absence" or "omission" are not referring expressions. (We might more perspicuously say, for example, that there are cases of causation by the absence or omission of something, rather than cases of causation by the presence of an absence or omission.) I'll concede, for the sake of argument, that some such cases of causation by absence or omission obtain. But the idea that causes are things might still hold true with respect to the sort of causal explanations which interest me, namely potential causal explanations for why there is something rather than nothing. In typical cases of causation by absence/omission, an alleged absence or omission is merely one cause of the effect in question, rather than the sole cause. If, for example, my failure to eat causes my death, the absence of digested food isn't the sole cause of my death. Other causes of my death will include various biological processes occurring within my body. But any causal explanation for why there is something rather than nothing, which

14 Thanks here to Johanna Seibt. 
proceeds by way of a causation by absence or omission, must be such that all of the causes for there being something rather than nothing are absences or omissionsotherwise such causal explanations fall prey to the objections to causal answers to the Question which I described earlier in this paper. It is difficult to see what such a causal explanation, solely in terms of absences or omissions, could be. ${ }^{15}$

But let's say we drop my so-called "double standard" and concede that, like grounding, causation can occur even when there exists nothing to do the causing. In this case perhaps we could conceivably offer a causal explanation for why there is something rather than nothing. I would personally welcome this result. This paper is primarily concerned, not to establish that causal explanations cannot serve as answers the Question (although I think this is true), but rather to establish that grounding explanations might serve as answers to the Question. More generally, I would like to establish that there are modes of explanation which can in principle serve as explanations for why there is something rather than nothing. If causal explanations as well as grounding explanations can do the trick, so much the better.

Objection: Truths require truthmakers (cf. David 1997: Ch. 8). But the grounding explanations for why there is something rather than nothing which I discuss above appeal to true subjunctive conditionals which seem to lack truthmakers. ${ }^{16}$ For example, the phenomenalist answer to the Question appeals to various true subjunctive conditionals involving sense data. Such conditionals lack truthmakers, at least if phenomenalism is true. Non-phenomenalists can provide truthmakers for the conditionals in question. For example, the truthmaker for the conditional "if I were to be in such-and-such circumstances then I would have such-and-such tableish visual impressions" is made true by a number of factors, not least of which is the fact that there exists a table apt to produce the visual impressions in question. But since the phenomenalist thinks the conditionals in question ground the existence of the table, they cannot, on pain of circularity, appeal to the existence of the table to ground the truth of the conditionals. This point is acknowledged by Pelczar, who defends the sort of phenomenalism I discuss above. Pelczar argues that "potentials for experience" are ungrounded, although which potentials for experience obtain is constrained by which other potentials for experience obtain (Pelczar 2019: 589). Put

\footnotetext{
15 One option which has been suggested to me is that there is something rather than nothing because when there was nothing, there was nothing to prevent there being something. (This potential explanation by omission was suggested to me by Johanna Seibt. Thanks also to an anonymous referee for help formulating the potential explanation.) I don't think this is a promising explanation. Simply because there is nothing preventing some state of affairs from obtaining, it doesn't follow that the state of affairs will obtain. Assume for reductio that a state of affairs does obtain if there is nothing preventing that state of affairs from obtaining. Now consider some indeterministic process-say, the decay of a radium atom. If this process is truly indeterministic then, for any time at which the atom might decay, there is nothing preventing the decay of the atom at that time (assuming the atom has not already decayed). The atom should presumably decay, then, as soon as it is physically possible for it to do so. In this case the process wouldn't really be indeterministic, since the radium atom must decay as soon as it is physically possible for it to do so. Since such indeterministic processes seem to be possible, however, we've reached a reductio of our initial assumption, that there being nothing to prevent some state of affairs from obtaining is a sufficient condition for that state of affairs to obtain.

16 These sorts of "brute" subjunctive conditionals are sometimes explicitly rejected on the grounds that they lack truthmakers. See, e.g., Adams (1977), Hasker (1989: 23-24) and Sider (2001: 36).
} 
in terms of subjunctive conditionals: some subjunctive conditionals regarding sense data are true, and some are false, but nothing grounds the truth or falsity of any of these conditionals (although the truth values of some of these conditionals are constrained by the truth values of other conditionals).

Response: Perhaps it's right that the subjunctive conditionals I appeal to in the grounding explanations discussed above lack truthmakers. And perhaps we can go a step further and say that the grounding explanations discussed above are incompatible with a thesis related to the thesis that all truths require truthmakers, namely a thesis to effect that truth depends on being. Luckily, I reject both the thesis that all truths have truthmakers, as well as the thesis that truth depends on being, so I'm not very concerned. ${ }^{17}$

Notably, it is not just my proposed grounding explanations for why there is something rather than nothing which might run afoul of the alleged requirement that truths always have truthmakers, or that truth invariably depends on being. Arguably any explanation for why there is anything whatsoever (one of the two construals of the Question which concern me in this paper) will violate these requirements. Take, for example, the thesis that truths require truthmakers. The explanans in any explanation for why there is anything whatsoever plausibly must lack truthmakers. This is because if the explanans in question had truthmakers, and so were grounded in the existence of something, then on pains of explanatory circularity, they would be unable to explain why anything whatsoever exists - the existence of the truthmaker in question would explain why the explanans obtains, and the explanans would in turn explain why anything whatsoever exists.

Interestingly, the grounding explanations for why there is something rather than nothing discussed above are compatible with a thesis which is very closely related to the thesis that truths require truthmakers, namely the thesis that truth supervenes on being (a thesis endorsed by, e.g., Bigelow 1988: 130-133; Lewis 1992: 215-219). If the proposed answers to the Question discussed above are correct, then there does exist something for the truth of the subjunctive conditionals appealed to in those answers to supervene upon, namely those things the existence of which is grounded in the truth of those subjunctive conditionals. On the thesis that truth supervenes on being the existence of the things in question need not be explanatorily prior to the truth of the subjunctive conditionals. Rather, the existence of the things in question need only modally covary in an appropriate manner with the truth values of the relevant subjunctive conditionals. So, for example, recall the version of phenomenalism discussed above, according to which a table exists because of the truth of various subjunctive conditionals regarding sense data. Those subjunctive conditionals are true iff a table exists (i.e., it is true that, if someone were in such-and-such circumstances, then they would have such-and-such visual impressions, iff a table exists). So, the truth of the subjunctive conditionals supervenes on the existence of the table. So, the truth of the subjunctive conditional is compatible with the thesis that truth supervenes on being, whether or not it is compatible with the thesis that

17 For a general defense of the thesis that truths do not always require truthmakers, see Merricks (2007). 
truths always have truthmakers, or with the thesis that truth invariably depends on being.

\section{Conclusion}

The question "why is there something rather than nothing?" (the Question) asks us for an explanation. It may seem as if there couldn't be an explanation for why there is something rather than nothing, since any explanatory factor appealed to in the explanans may be expected to be one of the things for whose existence we seek an explanation. In this paper I've tried to show that finding an explanation for why there is something rather than nothing can seem like an impossible endeavor only if we work within the confines of a needlessly constricted account of the nature of explanation. Other philosophers (e.g., Lange) have made similar points. I've tried to continue the task undertaken by those earlier philosophers in making conceptual room for explanations capable of serving as answers to the Question. In particular I've argued that there are no conceptual barriers to our endorsing a grounding explanation for why there is something rather than nothing. Such explanations must take a special form, since they must be such that the grounds cited in those explanations do not appeal to anything's existence, while remaining capable of grounding something's existence. But I've argued that grounding explanations of this sort seem to be both conceivable and not so far removed from grounding explanations many of us are already willing to endorse. Insofar as these grounding explanations resemble grounding explanations many of us already endorse, we have a significant grasp on how such grounding explanations work. I have not endorsed any particular explanation for why there is something rather than nothing, and in fact for all that I've said there may be no explanation for why there is something rather than nothing. I hope to have pointed the way toward one potentially fruitful avenue for future research: we might try looking for grounding explanations of the relevant sort which cite, as the grounds cited in those explanations, the truth of certain subjunctive conditionals. I've described two potential explanations of this sort. One is already familiar from previous discussion of the Question, namely Leslie's axiarchist answer to the Question. The other, the phenomenalist answer to the Question, has not, to my knowledge, been previously discussed.

Acknowledgements Open access funding provided by University of Gothenburg. Thanks to anonymous referees, Rebecca Chan, Peter Finocchiaro, Anna-Sofia Maurin, Gabriel Rabin, Melanie Rosen, Pierre Saint-Germier, Johanna Seibt, Maetias Skipper, Alexander Skiles, Robin Stenwall, Naomi Thompson, Gustavo Fernandez Walker, Robbie Williams, the audience at a November 2018 Research Colloquium in Theoretical Analytical Philosophy at Aarhus University, and the audience at the 2019 Swedish Congress of Philosophy at Umeå University. Work on this paper was supported by Riksbankens Jubileumsfond.

Open Access This article is licensed under a Creative Commons Attribution 4.0 International License, which permits use, sharing, adaptation, distribution and reproduction in any medium or format, as long as you give appropriate credit to the original author(s) and the source, provide a link to the Creative Commons licence, and indicate if changes were made. The images or other third party material in this article are included in the article's Creative Commons licence, unless indicated otherwise in a credit line to the material. If material is not included in the article's Creative Commons licence and your intended use is 
not permitted by statutory regulation or exceeds the permitted use, you will need to obtain permission directly from the copyright holder. To view a copy of this licence, visit http://creativecommons.org/licen ses/by/4.0/.

\section{References}

Adams, R. M. (1977). Middle knowledge and the problem of evil. American Philosophical Quarterly, 14(2), 109-117.

Armstrong, D. M. (1997). A world of states of affairs. Cambridge: Cambridge University Press.

Azzouni, J. (2007). Ontological commitment in the vernacular. Nô̂s, 41(2), 204-226.

Bigelow, J. (1988). The reality of numbers: A physicalist's philosophy of mathematics. Oxford: Clarendon Press.

Bohn, E. (2018). Divine foundationalism. Philosophy Compass, 13(10), 1-11.

Brenner, A. (2016). What do we mean when we ask "why is there something rather than nothing?". Erkenntnis, 81(6), 1305-1322.

Callender, C. (2016). Thermodynamic asymmetry in time. In E. N. Zalta (Ed.), The Stanford Encyclopedia of Philosophy (winter 2016 ed.). Metaphysics Research Lab, Stanford University.

Fine, K. (2001). The question of realism. Philosophers' Imprint, 1, 1-30.

Glazier, M. (2016). Laws and the completeness of the fundamental. In M. Jago (Ed.), Reality making (pp. 11-37). Oxford: Oxford University Press.

Glazier, M. (2017). Essentialist explanation. Philosophical Studies, 174(11), 2871-2889.

Goldschmidt, T. (2013). Understanding the question. In T. Goldschmidt (Ed.), The puzzle of existence: Why is there something rather than nothing? (pp. 1-21). New York: Routledge.

Hasker, W. (1989). God, time, and knowledge. Ithaca: Cornell University Press.

Hempel, C. (2001). Science unlimited? In J. H. Fetzer (Ed.), The philosophy of Carl G. Hempel: Studies in science, explanation, and rationality (pp. 329-343). Oxford: Oxford University Press.

Kotzen, M. (2013). The probabilistic explanation of why there is something rather than nothing. In T. Goldschmidt (Ed.), The puzzle of existence: Why is there something rather than nothing? (pp. 215234). New York: Routledge.

Lange, M. (2013). Are some things naturally necessary? In T. Goldschmidt (Ed.), The puzzle of existence: Why is there something rather than nothing? (pp. 235-251). New York: Routledge.

Leibniz, G. W. (1998). Principles of nature and grace, based on reason. In R. S. Woolhouse \& R. Francks (Eds.), Philosophical texts (pp. 258-266). Oxford: Oxford University Press. (Originally published in 1714).

Leslie, J. (1979). Value and existence. Totowa: Rowman and Littlefield.

Leslie, J. (2001). Infinite minds: A philosophical cosmology. Oxford: Clarendon Press.

Lewis, D. (1992). Critical notice of Armstrong's: A combinatorial theory of possibility. Australasian Journal of Philosophy, 70, 211-24.

Maurin, A.-S. (2019). Grounding and metaphysical explanation: It's complicated. Philosophical Studies, 176(6), 1573-1594.

Merricks, T. (2007). Truth and ontology. Oxford: Oxford University Press.

Nozick, R. (1981). Philosophical explanations. Cambridge, MA: Belknap Press.

Pearce, K. L. (2017). Foundational grounding and the argument from contingency. In J. L. Kvanvig (Ed.), Oxford studies in philosophy of religion (Vol. 8, pp. 245-268). Oxford: Oxford University Press.

Pelczar, M. (2019). Defending phenomenalism. The Philosophical Quarterly, 69(276), 574-597.

Putnam, H. (2004). Ethics without ontology. Cambridge, MA: Harvard University Press.

Raven, M. J. (2015). Ground. Philosophy Compass, 10(5), 322-333.

Rescher, N. (2013). The rejectionist approach (from the riddle of existence). In R. L. Kuhn \& J. Leslie (Eds.), The mystery of existence: Why is there anything at all? (pp. 284-288). Hoboken: Wiley-Blackwell.

Rosen, G. (2010). Metaphysical dependence: Grounding and reduction. In B. Hale \& A. Hoffmann (Eds.), Modality: Metaphysics, logic, and epistemology (pp. 109-36). Oxford: Oxford University Press.

Rosen, G. (2017). Ground by law. Philosophical Issues, 27, 279-301.

Schaffer, J. (2009). On what grounds what. In D. J. Chalmers, D. Manley, \& R. Wasserman (Eds.), Metametaphysics (pp. 347-83). Oxford: Oxford University Press. 
Schaffer, J. (2017a). The ground between the gaps. Philosophers' Imprint, 17(11), 1-26.

Schaffer, J. (2017b). Laws for metaphysical explanation. Philosophical Issues, 27, 302-321.

Sider, T. (2001). Four-dimensionalism. Oxford: Clarendon Press.

Sober, E. (1983). Equilibrium explanation. Philosophical Studies, 43(2), 201-210.

Sorensen, R. (2017). Nothingness. In E. N. Zalta (Ed.), The Stanford encyclopedia of philosophy (fall 2017 ed.). Metaphysics Research Lab, Stanford University.

Sturgeon, N. L. (1988). Moral explanations. In G. Sayre-McCord (Ed.), Essays on moral realism (pp. 229-255). Ithaca: Cornell University Press.

Thompson, N. (2016). Grounding and metaphysical explanation. Proceedings of the Aristotelian Society, 116(1), 395-402.

van Inwagen, P. (1996). Why is there anything at all? Proceedings of the Aristotelian Society, 70, 95-110. Wilsch, T. (2015). The nomological account of ground. Philosophical Studies, 172(12), 3293-3312.

Publisher's Note Springer Nature remains neutral with regard to jurisdictional claims in published maps and institutional affiliations. 